\title{
COMPARATIVE ANALYSIS OF COMPETITIVE STATE ANXIETY AMONG TEAM SPORT AND
} INDIVIDUAL SPORT ATHLETES IN IRAN

Hossein Soltani*1, Zahra Hojati ${ }^{2}$, Seyed Reza Attarzadeh Hossini ${ }^{3}$

${ }^{1}$ Young Researchers and Elite Club, Torbat-e Heydarieh Branch, Islamic Azad University, Torbat-e Heydarieh, Iran.

${ }^{2}$ Department of Physical Education and Sport Sciences, Birjand Branch, Islamic Azad University, Birjand, Iran.

${ }^{3}$ Sport Physiology Faculty of Physical Education and Sport Sciences, Ferdowsi University of Mashhad, Mashhad, IR Iran

\begin{abstract}
Purpose: With respect to the fact that every sport field has its own special nature, the aim of present study was to compare competitive state anxiety among team sport and individual sport athletes in Iran. Material: The statistic sample included 120 male athletes, 60 athletes in individual sports (wrestling, taekwondo and karate) and 60 athletes in team sports (futsal, volleyball and basketball). The research instrument employed was the Persian version of the Competitive State Anxiety Inventory-2. This inventory was distributed among the subjects about 30 minutes before the first competition. Finally by one-way ANOVA data was analyzed. Results: The results indicated that the mean score of somatic anxiety and cognitive anxiety among individual sport athletes was significantly higher than that of team sport athletes $(\mathrm{p}<0.05)$. The levels of self-confidence of individual sports athletes was higher than that of team sports athletes, but the difference was not significant $(\mathrm{p}>0.05)$. Conclusion: It seems the being part of a team alleviates some of the pressure experienced by those who compete alone. It seems the individual sport athletes may be more exposed to evaluation and more engaged in their own skills and abilities than team sport athletes given that responsibility for performance is not distributed across several performers.
\end{abstract}

Keywords: competitive, state anxiety, cognitive anxiety, somatic anxiety, team sports, individual sports.

\section{Introduction}

Competitive anxiety is one of the most thoroughly examined topics in sport psychology literature. This is mainly due to the perceived detrimental effects anxiety has on performance, creating the negative view most individuals hold of this concept. Anxiety is defined as feelings of nervousness and tension caused by the environment or surrounding expectation that is related to 'arousal'. These demands are usually stressful, indicating to the athletes a perception of imbalance between the demand given and their abilities to fulfill the demand [1]. Dealing with competitive state anxiety is a main task for coaches because players and sport teams could not perform when they are under stress. Players could not perform their best as they usually could because of anxiety. Consequently, their performance is affected during the competition and they seldom achieve victory [2].

State anxiety is generally regarded as an unpleasant emotional reaction related to stressful situations, in which the arousal component is one inherent element [3]. An important distinction between arousal and anxiety is that anxiety involves interpretation of the situation as threatening, whereas arousal is unrelated to any such interpretations [4]. Moreover, anxiety has been suggested as a better predictor of the performance outcome than arousal when the tasks are of a more complex nature and contain a higher cognitive load [5].

Multidimensional theory was developed by [6]. The multidimensional theory proposed that anxiety three subscales cognitive anxiety, somatic anxiety and self-confidence. Cognitive anxiety is defined as "the mental component of anxiety and is caused by negative expectations about success or by negative self-evaluation". Second element of anxiety is somatic anxiety that "refers to the physiological and affective elements of the anxiety experience that develop directly from autonomic arousal" [6]. Martens et al. have suggested that somatic anxiety should affect performance in a curvilinear fashion, with both lower and higher levels of somatic anxiety being detrimental to performance. "It is likely to reach its peak at the onset of competition and dissipate once the contest begins". Therefore, somatic anxiety, due to its time course, is thought to have less of an influence on performance than doe's cognitive anxiety [6]. A third element of competitive state anxiety discussed by Martens et al. is selfconfidence. This encompasses the athlete's global perceptions of confidence. Although not originally proposed as a subcomponent of anxiety, Martens et al. have since included self-confidence in their study of the anxiety/performance relationship. They have proposed a positive linear relationship between self-confidence and performance [6].

The findings of various research works regarding competitive state anxiety in athletes have had contradictory results. Pigozzi, showed the skill level of athletes is an important factor for control of competitive state anxiety [7]. The research [8] confirmed that elite athletes have lower levels of competitive state anxiety than

(C) Hossein Soltani, Zahra Hojati,

Seyed Reza Attarzadeh Hossini, 2016

doi:10.15561/20755279.2016.0508 
non-elite athletes. The studies [9], [10] showed that the kind of sport, nature of sport (individual sport or team sport) and gender of athletes are affecting factors on their performance.

Howard compared the levels of cognitive State anxiety, Somatic state anxiety, and competitive trait anxiety for varsity athletes between team sports and individual sports. Results showed that Competitive State Anxiety scores for team sports and it was significantly higher than that of individual sport athletes [11]. Mohsenpour studied state anxiety among male athletes of individual and team sports and concluded that there was no significant difference between somatic factor of group and individual examinable items but athletes of major group obtained lower cognitive grades than individual athletes [12].

According to [13] anxiety levels before and during competition are not clear due to conflicting findings, various athletes have reported different levels of anxiety from much to low. Behzadi, Adem reported significant difference in levels of competitive state anxiety among team sports and individual sports athletes [14], [15]. In contrast, [16], [17] have not reported significant difference in high, moderate or low level of anxiety. It seems that the levels of competitive state anxiety in team and individual sport athletes are not clear. With respect to the fact that every sport field has its own special nature, and also the results of most of the researches done are not in accordance with each other, therefore lack of a comprehensive theory in this field made the author to take action and compare competitive state anxiety among team sport and individual sport athletes in Iran.

\section{Material and Methods}

\section{A. Participants}

The statistical population used in this study contained team sports (volleyball, basketball, futsal) and individual sports (thaekwondo, karate, and wrestling) in Iran. Samples were male volleyball, basketball, futsal, taekwondo, karate, and wrestling team players who had competed in the leagues and super leagues competition of Iran in 2012 year. The total number of subjects was 120 male athletes consisted of 60 athletes in individual sports and 60 athletes in team sports who participated in competitions of leagues and super leagues of Iran.

\section{B. Measures}

1. Demographic Questionnaire

Participants were asked to indicate their age, training experience, and skill level.

2. Competitive State Anxiety Inventory-2 (CSAI-2)

This measurement tool is often used in research studies in order to estimate the participants' cognitive and somatic types of anxieties, as well as their self-confidence [6]. The test requires the subjects to choose the answer that corresponds with how they feel now, right now. Cognitive anxiety items are numbers $1,4,7,10,13,16,19,22$, and 25 . Somatic anxiety items are numbers 2, 5, 8, 11, 14 (reverse), 17, 20, 23, and 26. Self-confidence items are numbers 3, 6, 9, 12, 15, 18, 21, 24, and 27. Scoring of the CSAI-2 was achieved by the following way. Persons rated how they were feeling right at that moment by circling one of the presented answers. The four-presented answers included not at all (1), somewhat (2), moderately so (3) and very much so (4). The final scores for each subscale range from 9 to 36, with 9 indicating low anxiety/confidence and 36 indicating high anxiety/confidence [6]. The validity of this questionnaire was confirmed by professors and the reliability was measured by Cronbach's Alpha ("=0.89). In addition, internal reliability of this questionnaire was reported by Peter, 2007 as 85.75 , and 0.83 respectively [18].

\section{Procedures}

At first, the researcher visited coaches from the various teams that had been selected and explained the nature of the study and in the second stage explained the study to the athletes and distributed materials containing a letter describing the study and informed consent forms. At the third stage, Personal Information Questionnaire and state Competitive Anxiety Inventory (CSAI-2) for both elite and non-elite players were administered to the subjects within 30 minutes prior to the start of the competition and the nature of study was described at the top of the questionnaire to the subjects. Each questionnaire took approximately 5 minutes to complete.

\section{Statistical Analysis}

In order to calculate measures of central tendency and variability measures descriptive statistics was utilized. At first Levene's test checked homogeneity of variances between sets of scores. After making sure of variances homogeneity, One way analysis of variance was conducted for between group's comparisons, then the hypotheses were examined at $\mathrm{P}<0.05$.

\section{Results}

Table 1 shows that the amount of Levene Statistic of somatic anxiety, cognitive anxiety and self-confidence are $0.172,0.390$ and 0.645 respectively. The obtained "P" value is $0.679,0.533$ and 0.423 respectively $(\mathrm{P}>0.05)$. Therefore, team sport and individual sport athletes are homogenous in term of studied variable.

Table 2 shows the scores of cognitive anxiety, somatic anxiety, and self-confidence in team and individual sport athletes. 
The one-way ANOVA results indicated that means of cognitive anxiety in team and individual sport athletes are 17.23 and 15.96 respectively. The standard deviations of cognitive anxiety in team and individual sport athletes are 4.45 and 4.05 respectively. The obtained " $F$ " is 5.302 and "P" value is 0.022 . The one-way ANOVA results indicated that team sport athletes had significantly lower levels of cognitive anxiety compared with individual sport athletes $(\mathrm{P}<0.05)$.

The one-way ANOVA results indicated that means of somatic anxiety in team and individual sport athletes are 15.74 and 14.49 respectively. The standard deviations of somatic anxiety in team and individual sport athletes are 4.20 and 4.12 respectively. The obtained " $F$ " is 5.41 and "P" value is 0.021 . The one-way ANOVA results indicated that team sport athletes had significantly lower levels of somatic anxiety compared with individual sport athletes $(\mathrm{P}<0.05)$.

The one-way ANOVA results indicated that means of self-confidence in team and individual sport athletes are 26.90 and 26.08 respectively. The standard deviations of self-confidence in team and individual sport athletes are 3.56 and 3.91 respectively. The obtained " $F$ " is 2.11 and "P" value is 0.148 . The one-way ANOVA results indicated that there was no significant difference between the scores of self- confidence among team sport and individual sport athletes in Iran $(\mathrm{P}>0.05)$.

Table 1. Levene's Homogeneity Test

\begin{tabular}{llll}
\hline Variables & Groups & Levene Statistic & Sig. \\
\hline Cognitive Anxiety & Team game and Individual game Players & .390 & 0.533 \\
Somatic Anxiety & Team game and Individual game Players & .172 & 0.679 \\
State Self Confidence & Team game and Individual game Players & 0.645 & 0.423 \\
\hline
\end{tabular}

Table 2. Mean Values and One- Way ANOVA of Cognitive Anxiety, Somatic Anxiety and Self-Confidence between Team Sport and Individual Sport Athletes in Iran ( $N=120)$

\begin{tabular}{llllll}
\hline Variables & Groups & $\mathbf{N}$ & $\mathbf{M} \pm \mathbf{S D}$ & $\mathbf{F}$ & Sig. \\
\hline \multirow{2}{*}{ Cognitive anxiety } & Individual Sport Athletes & 60 & $17.23 \pm 4.45$ & \multirow{2}{*}{5.302} & \multirow{2}{*}{0.022} \\
& Team Sport Athletes & 60 & $15.96 \pm 4.05$ & & \\
Somatic Anxiety & Individual sport Athletes & 60 & $15.74 \pm 4.20$ & \multirow{2}{*}{5.41} & 0.021 \\
& Team Sport Athletes & 60 & $14.49 \pm 4.12$ & & \\
Self-Confidence & Individual Sport Athletes & 60 & $26.90 \pm 3.56$ & \multirow{2}{*}{2.11} & 0.148 \\
& Team Sport Athletes & 60 & $26.08 \pm 3.91$ & &
\end{tabular}

\section{Discussion}

One-way ANOVA results indicated that the scores of cognitive anxiety among individual sport athletes was higher than team game athletes scores and there was a significant difference in cognitive anxiety between individual game athletes and team game athletes in Iran $(\mathrm{p}<0.05)$. It may be due to the fact that fear of failure is a stronger predictor of cognitive anxiety for individual sport athletes than for team sport athletes given the potential accountability for failure placed on individual sport athletes. Athletes who participate in individual sports have also been found to experience more anxiety than those who play team sports [19]. For athletes in high-contact sports and martial arts such as karate, thaekwondo and wrestling the possibility of getting hurt can also be a source of anxiety. It seems that in individual sports, the athletes are more engaged in their own skills and abilities, while in team sports such as volleyball, basketball, and futsal, they are affected by their team members and their performance will depend on the performance of the group. The role assigned to the athlete in team sports may not correspond to their inner role. An additional factor that causes cognitive anxiety is the expectation of success. Some athletes rise to the challenge imposed by public expectation while others can choke. The trick is to become sufficiently 'psyched-up' without becoming 'psyched-out' [19].

One-way ANOVA results indicated that is a significant difference in somatic anxiety between team sport athletes and individual sport athletes in Iran $(\mathrm{P}<0.000)$. It seems that athletes who participate in individual sports have been found to experience more anxiety than those who play team sports. Common sense suggests that being part of a team alleviates some of the pressure experienced by those who compete alone [20]. This finding is consistent with predictions that competitive situations elicit both cognitive and somatic anxiety. An alternative explanation is that the physiological arousal demands of the specific sports tested confounded the individual team comparison. Thaekwondo, karate and wrestling (individual sports) and volleyball, basketball and futsal (team sports) used in this comparison; seem to demand moderate arousal levels for optimal performance. Thus, the significant difference in somatic anxiety between individual and team games may simply reflect the differential arousal demands of the sport chosen for comparison rather than significant differences between these sport types $[11,15,21]$. In addition, Martin and Hall research demonstrated that Skaters experienced grater somatic and cognitive anxiety prior to an individual competitive event than prior to a team competition. Maybe this is because of a diffusion of responsibility that occurs in the team framework but not in an individual framework [22]. Researches comparing athletes competing in team sports with those competing in individual sports have found 
that athletes competing in individual sports reported significantly higher somatic anxiety than team sports athletes. This finding is supported by Simon 1977, Howard and Zeng 2003, Adem et al. 2010.

One-way ANOVA results indicated that mean difference of self-confidence in individual sport athletes and team sport athletes were not significant $(p>0.05)$. It may be related to nature of these sports because in team sports a diffusion of responsibility occurs in the team framework that can decrease competitive state anxiety and increase sate self-confidence and on the other hand in individual sports athletes are forced to stand alone, to fight alone, and to perform alone. Decisions must be made by the athletes in the moment. If the athletes fail, it is on his/her on shoulders, and if s/he succeeds, that too is his/her success alone.

This makes a strong feeling of self-confidence and self-reliance. It instills the knowledge that one is capable of acting alone against challenging circumstances. On the other hand, in team sports a diffusion of responsibility occurs in the team framework that can decrease anxiety and improve self-confidence. So while team sports offer a lot of benefits to athletes in terms of teamwork and sportsmanship, individual sports should not be overlooked. It seems athletes of team and individual sports used effective coping strategies to manage anxiety before getting out of hand. Additionally, exposing athletes to psychological training programs from an early age is probable to have a very positive influence on their levels of selfconfidence, which may be transferred into their adult sporting careers [23].

\section{Conclusion:}

The present study found that the team game athletes experience lower levels of competitive state anxiety than individual games athletes. In conclusion, individual games athletes are more prone to feel the effects of anxiety on performance than team games athletes.

Furthermore individual sports athletes may be more exposed the evaluation than team sport athletes given that responsibility for performance is not distributed across several performer. In other word in individual sports, the athlete is more engaged in their own skills and abilities, while in team sports such as volleyball, basketball and futsal, they are affected by their team members and their performance will depend on the performance of the group. The role assigned to the athlete in team sports may not correspond to their inner role. Therefore it is suggested that coaches and athletic authorities of participating teams in sport leagues employ sport psychologist to teach and prepare comprehensive planning to develop psychological skills and suitable strategies for coping competitive anxiety specific non elite athletes and individual games athletes and also help them to eliminate negative thoughts and focus on the positive outcomes and not on the chances of failure by the help of sport psychologists.

\section{Conflict of interests}

The authors declare that there is no conflict of interests.

\section{References}

1. Gould D, Greenleaf C, \& Krane V. Advances in sport Psychology. (2nd Ed.). s.1.: Champaign, IL: Human Kinetics; 2002.

2. Patsiaouras A, Papanikolaou Z, Haritonidis K, Nikolaidis D, Keramidas P. The use of the person-centered approach for the reduction of the state-trait anxiety in volleyball players. Journal of Sport Psychology 2008;10(2):24-30.

3. Woodman T, \& Hardy L. Handbook of sport psychology, John Wiley \& Sons; 2011.

4. Hammermeister J, \& Burton D. Stress, Appraisal, and Coping Revisited: Examining the Antecedents of Competitive State Anxiety with Endurance Athletes. Sport Psychologist, 2001;15(1):66-90. doi:10.1123/tsp.15.1.66

5. Arent, S. M., \& Landers, D.M. Arousal, anxiety, and performance: A reexamination of the inverted- $U$ hypothesis. Res Q Exerc Sport. 2003;74(4):436-44. doi: 10.1080/02701367.2003.10609113

6. Martens R, Burton D, Vealey RS, Bump LA, \& Smith DE. Competitive anxiety in sport. Champaign, IL: Human Kinetics; 1990.

7. Pigozzi F. Role of exercise stress test in master athletes. British Journal of Sports Medicine. 2005;39(8):527531. doi:10.1136/bjsm.2004.014340

8. Soltani, H. Comparative Analysis of Competitive State Anxiety among Elite and Non-Elite karate Athletes in Iran. Advances in Environmental Biology, 2013;7(7):1244-1248.

9. Grossbard JR, Smith RE, Smoll FL, Cumming SP. Competitive anxiety in young athletes: Differentiating somatic anxiety, worry, and concentration disruption. Anxiety, Stress \& Coping. 2009;22(2):153-166. doi:10.1080/10615800802020643

10. Cristina, A. Anxiety and performance in table tennis players. Journal of Sport Psychology, 2004;24:185-204.

11. Howard, z. a. The Differences between Anxiety and self- confidence between Team and Individual sports college varsity Athletes. International Sports Journal, 2003;7(1):28-33.

12. Mohsenpour F. Studying and comparing of competitive state anxiety of men athletes in individual and group majors of championship contests of institutions in Khuzestan province. [PhD thesis]. Shahid Chamran University of Ahvaz; 2003. 
13. Mellalieu SD. A competitive anxiety review: recent directions in sport psychology research. New York: Nova Science Publishers; 2006.

14. Behzadi F, Mohammadpour A, Hedayatikatooli A, \& Nourallahi H. A Description and Comparison of Personality Traits of Competitive Individual and Team Athletes. Annals of Biological Research, 2012;3:3640.

15. Adem, C. Comparison of pre and post-game state and trait anxiety levels of individual and team athletes. Journal of Human Sciences, 2010;7(1):193-206.

16. Passand F. Studying and comparing of the amount of the competitive state anxiety in individual and team majors of women participating in the second students' sports Olympiad across the country [M thesis]. Tarbiat Moalem University: Iran; 1997.

17. Perry J.D. and Williams, J. M. Relationship of intensity and direction of competitive trait anxiety to skill level and gender in tennis. Sport Psychologist, 1998;12:169-179.

18. Terry Peter $\mathrm{C}$, Munro Angus. Mood and anxiety scores predict winning and losing performances in tennis. In: 43rd Australian Psychological Society Annual Conference (APS 2008): Psychology Leading Change, 23-27 Sep 2008, Hobart, Australia; 2008.

19. Flowers R, \& Brown C. Effects of sport context and birth order on state anxiety. Journal of Sport Behavior, 2002;25:41-56.

20. Arlin C. Guide. Sports and Performance Anxiety. 2010.

21. Simon JA, \& Martens R. S.C.A.T. as a predictor of A-states in varying competitive situations. In: D. M. Landers \& R. W. Christina (Eds.), Psychology of Motor Behaviour and Sport (Vol. 2), Human Kinetics: Champaign, IL; 1977, p. 146-156.

22. Ahmed, Shamshad. Psychological basis of physical education. India: Gayan books; 2005.

23. Mamassis, G. D. The effects of mental training program on juniors pre competitive anxiety, self-confidence and tennis performance. Asian Social Science, 2004;10(18):90-95.

Information about the authors:

Hossein Soltani; Sport Psychologist, Assistant Professor of Physical Education and Sport Sciences; http://orcid.org/00000003-3985-2385; soltani_hn@yahoo.com; Islamic Azad University; P.O.Box 140, Torbat-e-Heydareih, Iran.

Zahra Hojati; Assistant Professor; http://orcid.org/0000-00033405-0631; hojjati_z@yahoo.com; Islamic Azad University; Birjand, Khorasan-e-Jonubi, Iran.

Seyed Reza Attarzadeh Hossini; soltani_hn@yahoo.com; http://orcid.org/0000-0002-9059-3262; Ferdowsi University of Mashhad; Razavi Khorasan Province, Mashhad, Vakilabad Highway, 9177948974, IR Iran.

Cite this article as: Hossein Soltani, Zahra Hojati, Seyed Reza Attarzadeh Hossini. Comparative analysis of competitive state anxiety among team sport and individual sport athletes in Iran. Physical education of students, 2016;5:57-61. doi:10.15561/20755279.2016.0508

The electronic version of this article is the complete one and can be found online at: http://www.sportpedu.org.ua/html/arhive-e.html

This is an Open Access article distributed under the terms of the Creative Commons Attribution License, which permits unrestricted use, distribution, and reproduction in any medium, provided the original work is properly cited (http://creativecommons.org/licenses/by/4.0/deed.en).

Received: 15.09 .2016

Accepted: 01.10.2016; Published: 28.10.2016 